\title{
Dichotic listening and manual performance in relation to magnetic resonance imaging after closed head injury
}

\author{
HARVEY S LEVIN, * WALTER M HIGH, JR, * DAVID H WILLIAMS, * \\ HOWARD M EISENBERG,* EUGENIO G AMPARO, $†$ FAUSTINO C GUINTO, JR, $\dagger$ \\ JEFF EWERT $\ddagger$
}

From the Division of Neurosurgery* and the Department of Radiology, $\uparrow$ The University of Texas Medical Branch, Galveston and Department of Psychology, $\ddagger$ University of Houston, Texas, USA

SUMMARY In order to investigate post-traumatic hemispheric disconnection effects, dichotic listening and intermanual tasks were administered to 69 patients who had sustained a closed head injury of varying severity. The manual tasks consisted of naming objects palpated in either hand, transfer of postures from one hand to the other and writing. Consistent with predictions, the degree of ear asymmetry in dichotic listening performance was directly related to the severity of the head injury as reflected by the degree of impaired consciousness. Depth and localisation of parenchymal lesion characterised by magnetic resonance imaging were also related to the degree of ear asymmetry. Parenchymal lesions situated in sites which could potentially interfere with callosal auditory or geniculocortical pathways produced a greater disparity in response to left versus right ear inputs as compared with parenchymal lesions in areas such as the frontal lobes which are purportedly unrelated to asymmetries in dichotic listening performance. The results provide further evidence for the effect of multifocal brain lesions involving the white matter on tasks which require intra and/o interhemispheric integration.

Strich ${ }^{1}$ first published microscopic findings of diffuse axonal injury (DAI) which she attributed to mechanical disruption (that is, shearing, tearing) of nerve fibres at the moment of impact in severe closed head injury (CHI). Focal haemorrhages involving the corpus callosum, the dorsolateral quadrant(s) of the rostral brainstem and the white matter of the superior cerebellar peduncle are frequent pathological findings in DAI.$^{1-5}$ Degeneration of the cerebral white matter, which presumably occurs over periods of up to several months, has been implicated in lateral ventricular enlargement ${ }^{1256}$ and long tract signs such as ataxia. ${ }^{7}$

Consistent with disruption of intra and interhemispheric white matter connections in DAI, clinical reports have documented neurobehavioural disturbances such as ideomotor apraxia using the left hand, alexia without agraphia and tactile anomia for objects

Correspondence to: Harvey S Levin, PhD, Division of Neurosurgery D-73, The University of Texas Medical Branch, Galveston, Texas 77550 , USA.

Received 11 October 1988 and in revised form 10 March 1989. Accepted 21 March 1989 palpated by the left hand. ${ }^{8-10}$ Utilising the dichotic listening technique, Alexander and Warren ${ }^{11}$ recently reported a survivor of severe $\mathrm{CHI}$ who exhibited an exaggerated right ear advantage (that is, left ear suppression), a finding which the investigators attributed to a haemorrhagic lesion in the callosal auditory pathways. Although neuropathologic findings by Oppenheimer ${ }^{12}$ indicated the presence of DAI and corpus callosum lesions in two patients who sustained relatively mild head injuries and died from other causes, more recent neuropathological and antemortem magnetic resonance imaging (MRI) studies ${ }^{1314}$ have shown that deep white matter lesions are generally restricted to $\mathrm{CHI}$ which produces coma. This positive relationship between impairment of consciousness and depth of lesion is also compatible with previous experimental work in nonhuman primates by Ommaya and Gennarelli. ${ }^{15}$ In view of previous studies ${ }^{16-20}$ implicating nontraumatic brain lesions in the auditory interhemispheric connections, geniculocortical pathways and temporal cortex in abnormal dichotic listening, it is plausible that the localisation of brain lesion is related to ear asymmetry 
in performance by head injured patients. Consequently, this study evaluated the relationship between severity of acute $\mathrm{CHI}$, depth and localisation of intracranial lesion defined by MRI, and neurobehavioural evidence of hemispheric disconnection.

\section{Methods}

\section{Patients}

Selection criteria for this prospective study included hospitalisation for $\mathrm{CHI}$ of varying severity, resolution of post-traumatic amnesia, a negative history of antecedent neuropsychiatric disorder (including previous hospitalisation for head injury or chronic substance abuse) and an age range of 15 to 60 years. This report is confined to right handed patients to simplify analysis of hemispheric asymmetries which are known to differ in those that are left handed. We studied 69 right-handed patients with a mean age of 25.6 years $(S D=9.9)$ and a mean education of 11.8 years $(\mathrm{SD}=2 \cdot 4)$ who sustained $\mathrm{CHI}$ of varying severity (table 1 ). As shown in this table, the interval from injury to the examination tended to be longer in more severely injured patients. All patients were hospitalised in Galveston (The University of Texas Medical Branch) or Houston (Medical Center Del Oro) at the time of examination or had been discharged within three months of the study. Following the guidelines of a recent three centre study, ${ }^{21}$ a minor head injury was defined as loss of consciousness for no longer than 15 minutes, a Glasgow Coma Scale (GCS) $)^{22}$ score of 13 to 15 on admission and for the duration of the hospital stay, a normal neurological examination, and normal findings on the first computed tomography (CT) scan (if performed). Patients with GCS scores in the 13 to 15 range who had a positive CT scan (that is, evidence of a high density lesion, brain swelling) and/or intracranial surgical procedures (for example, repair of depressed fracture) were grouped with the moderate to severe injuries (table 1). Intracranial lesions visualised by MRI, which were undetected by $\mathrm{CT}$, were not considered in the classification of severity of injury.

Thirteen right handed controls, mean age 24.0 years (SD $=7 \cdot 1)$, mean education 12.1 years $(S D=1.7)$, were also tested. All patients and controls passed an auditory screening test given to each ear separately and to both ears simultaneously.

\section{Procedures}

\section{Dichotic listening}

The dichotic tape consisted of six consonant vowel (C-V) nonsense syllables (ta, pa, ka, ga, ba, da). Pairs of $\mathrm{C}-\mathrm{V}$ syllables were presented simultaneously at equal volumes to the right and left ears via earphones. The patient was instructed to call out the syllables presented on each of 60 trials. Earphones were reversed to the opposite ears after the first 30 trials to mitigate confounding by any possible subtle differences in their output. A laterality index [(right ear responses-left ear responses)/(right ear responses + left ear responses)] $\times 100$ was computed for the correct responses given by each individual.

Other measures of hemispheric disconnection

Patients were asked to write two sentences with each hand to dictation. ${ }^{23}$ They were asked to identify hidden common household objects by palpating them with either hand ${ }^{23}$ and tested for matching postures with the ipsilateral or contralateral hand, in the absence of visual cues. ${ }^{16} 17$ The examiner placed the patient's hand and fingers (hidden from the patient's view) in one of 10 positions followed immediately by returning the hand to the resting position. The patient was asked to then duplicate the posture using either the same hand or the contralateral hand.

\section{Magnetic Resonance Imaging}

The MRI scans were obtained in Houston and Galveston within one week of the neurobehavioural testing. MRI was performed in Houston on a 0.35 Tesla magnet with a proton resonant frequency of $15 \mathrm{MHz}$, with imaging in the transaxial and coronal planes using the spin-echo technique, slice thickness $7 \mathrm{~mm}$ and slice interval $3 \mathrm{~mm}$. The repetition time (TR) was $2000 \mathrm{~s}$ and echo times (TE) were 38 and $56 \mathrm{~ms}$. MRI was performed in Galveston on the Teslacon System using a 0.6 Tesla magnet with a proton resonant frequency of $25.4 \mathrm{MHz}$. Images were obtained in contiguous $8 \mathrm{~mm}$ slices in the transaxial and coronal planes using two spin echo (SE) sequences primarily: (a) repetition time (TR) was $500 \mathrm{~ms}$ and echo time (TE) was $32 \mathrm{~ms}$ and $(b) \mathrm{TR}=2000 \mathrm{~ms}$ and $\mathrm{TE}=$ $60 \mathrm{~ms}, 120 \mathrm{~ms}$. Two radiologists interpreted the neuroimaging findings independently of other data on the severity of the head injury and hemispheric disconnection symptoms. Radiologists also coded the MRI results on research forms which were compatible with computer entry. Intracranial abnormalities on MRI were coded as lesions provided that they were present on both the first and second echoes of $\mathrm{T}_{2}$-weighted images.

\section{Results}

\section{Dichotic listening}

Effects of severity of head injury. Figure 1 depicts a box plot showing the median and interquartile range of the laterality index for the control group and the patients who are divided into subgroups according to the severity of their head injury, and the depth and localisation of the brain lesion. Laterality indices for patients and controls (see table 1) on the dichotic listening task were ranked and an analysis of variance was performed on the ranks to test the presence of a difference in asymmetry of performance across the control $(\mathrm{n}=13)$, minor $\mathrm{CHI}(\mathrm{n}=7)$, and moderate to severe $\mathrm{CHI}(\mathrm{n}=62)$ groups. As reflected by the greater laterality index for moderate to severe injuries shown in fig 1 , the presence of a group effect for asymmetry in ear scores was confirmed $(F=3 \cdot 12, p<$ 0.05). Post hoc comparisons revealed that the moderate to severe $\mathrm{CHI}$ groups had a significantly greater right ear advantage in dichotic listening performance than the control group. There were no differences between the mild versus moderate/severe $\mathrm{CHI}$ groups in age or education. Deviation from the predominant pattern of right ear advantage in the head injured patients is also reflected in fig 1 which 
Table 1 Demographic characteristics, clinical features and dichotic listening performance in head injured patients and control sußfec

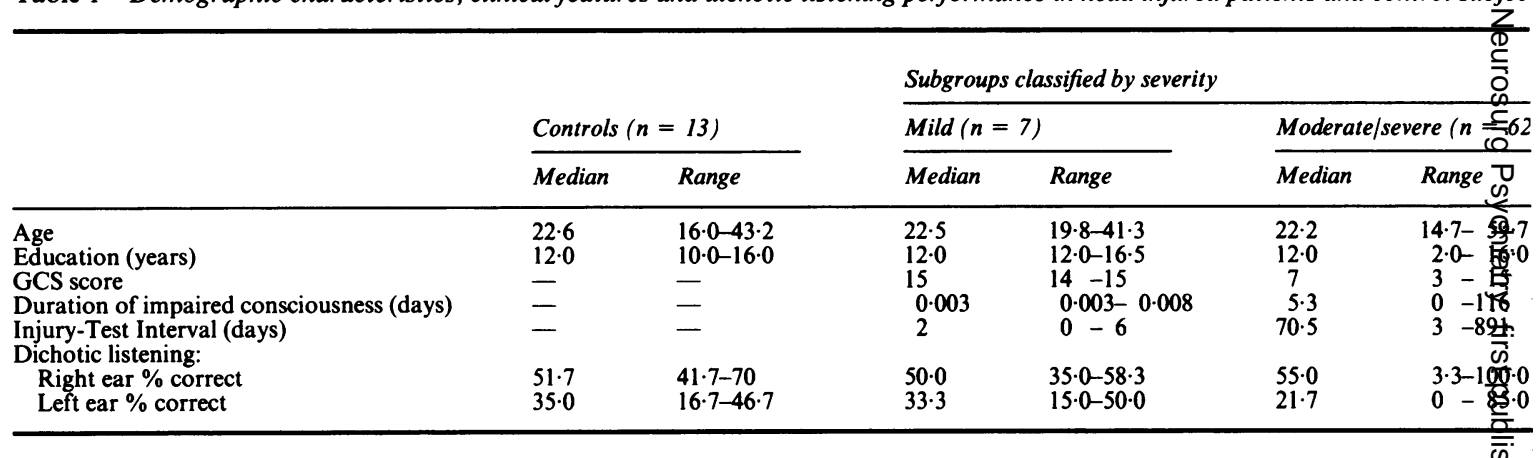

depicts a few cases of left ear advantage which fell outside the range of the control group. Of the eight CHI patients who exhibited a left ear advantage (fig 1), four sustained severe head injury whereas two had moderate and two had mild injuries.

Depth of brain lesion. To elucidate the role of white matter injury in the exaggerated right ear preference of the moderate to severely injured patients, a subgroup with MRI findings of no lesions and/or cortical lesions $(\mathrm{n}=16)$ was compared to patients with deeper parenchymal lesions including white matter $(n=42)$ and to controls $(n=13)$. The four patients with only extradural lesions were excluded from this analysis. Of the 42 patients with deep parenchymal lesions, 39 also had cortical lesions, two patients had an extradural (but no cortical) lesion and a single patient had no additional lesion. The centre box plot in fig 1 shows the degree of right ear advantage in patients with deep parenchymal lesions compared with the subgroup
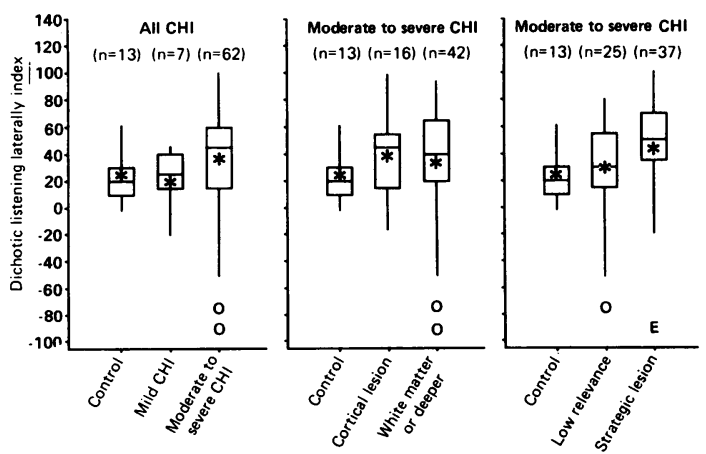

Fig 1 Box plot depicting laterality index for dichotic listening as a function of severity of head injury, depth and localisation of brain lesion visualised by MRI. The median $\left.{ }^{*}\right)$, mean (central horizontal bar), 75th percentile (upper width of box), 25th percentile (lower width), highest score (upward extension of vertical line) and lowest score (downward extension of vertical line) are given for each group. with cortical lesions and the control subjects. Al- $\stackrel{\mathbb{Q}}{2}$ though the overall $\mathrm{F}$ value $(2 \cdot 23)$ for comparing these $\%$ three groups on the mean ranks of the laterality index $\vec{\circ}$ was not significant, the patients with white matter lesions had a significantly greater right ear advantage $\vec{\omega}$ than control subjects $(\mathrm{p}<0.05)$. In contrast, the laterality index of the patients with cortical lesions was not significantly different from that of the other two groups. As summarised in table 1, the two $\mathrm{CHI}$ groups $\mathrm{N}$ divided according to the depth of brain lesion were $\vec{\circ}$ comparable in their GCS scores, age and education. However, the duration of impaired consciousness tended to be longer in the patients with deep lesiofso than the subgroup with cortical lesions.

Dichotic listening in relation to intrahemispheric localisation of lesion

The MRI findings of head injured patients were reviewed to identify the intrahemispheric localisatio of the lesion (table 1). In order to compare subgroups $\stackrel{\odot}{\infty}$ thus differentiated but who were otherwise compara-. ble in the severity of impaired consciousness, patients who sustained minor CHI were excluded from the analysis. Of the 62 patients, $25(40 \%)$ had a lesion visualised by MRI which was considered to have å potential influence on ear asymmetry in dichotic $\stackrel{\square}{\triangle}$ listening performance. Based on the dichotic listening $\overrightarrow{\vec{F}}$ study of Damasio and Damasio ${ }^{18}$ which localised 3 lesions according to CT templates, we classified patients with MRI-defined lesions relevant to earọ asymmetry as follows: temporal lobe cortex $(n=10)$, corpus callosum $(n=3)$, posterior lateral ventricular region $(n=3)$, geniculocortical pathways $(n=4)$ and:some combination of these sites $(n=5)$. To analyse 3 . the effects of intrahemispheric localisation of lesion, the laterality index was compared for these 25 patients 3 with strategic lesion sites and the 37 patients whose MRI defined lesions were considered to be irrelevant 5 (for example, frontal or occipital lesions) to asym- $\frac{D}{3}$ metry in dichotic listening performance.

Figure 1 shows a trend of greater right ear advan- $N$ tage in the 25 patients whose brain lesions were 


\begin{tabular}{|c|c|c|c|c|c|c|c|}
\hline \multicolumn{4}{|c|}{ bgroups classified by depth of lesion* } & \multicolumn{4}{|c|}{ Subgroups classified by localisation of lesion $\dagger$} \\
\hline $\begin{array}{l}.2 \\
.0 \\
.5 \\
.5 \\
.5\end{array}$ & $\begin{array}{c}15 \cdot 7-40 \cdot 1 \\
2 \cdot 0-15 \cdot 0 \\
3-15 \\
0-30 \\
3-891\end{array}$ & $\begin{array}{c}21 \cdot 0 \\
12 \cdot 0 \\
7 \\
6 \cdot 5 \\
73 \cdot 5\end{array}$ & $\begin{array}{c}14 \cdot 7-59 \cdot 7 \\
7 \cdot 0-16 \cdot 0 \\
3-15 \\
0-116 \\
3-610\end{array}$ & $\begin{array}{c}21 \cdot 1 \\
12 \cdot 0 \\
7 \\
4 \cdot 0 \\
59\end{array}$ & $\begin{array}{c}14 \cdot 7-59 \cdot 7 \\
2 \cdot 0-15 \cdot 0 \\
3-15 \\
0-102 \\
3-891\end{array}$ & $\begin{array}{c}22 \cdot 9 \\
12 \cdot 0 \\
6 \\
10 \cdot 0 \\
90\end{array}$ & $\begin{array}{c}15 \cdot 5-49 \cdot 3 \\
7.0-16.0 \\
3-15 \\
0.018-116 \\
3-502\end{array}$ \\
\hline $\begin{array}{l}.0 \\
.7\end{array}$ & $\begin{array}{c}28 \cdot 3-100 \\
0-48 \cdot 3\end{array}$ & $\begin{array}{l}55 \cdot 0 \\
22 \cdot 5\end{array}$ & $\begin{array}{l}3.3-96.7 \\
3 \cdot 3-85.0\end{array}$ & $\begin{array}{l}53 \cdot 3 \\
23 \cdot 3\end{array}$ & $\begin{array}{c}8.3-90 \\
10.0-78.3\end{array}$ & $\begin{array}{l}68 \cdot 3 \\
20 \cdot 0\end{array}$ & $\begin{array}{ll}3 \cdot 3 & -100 \\
0 & -85\end{array}$ \\
\hline
\end{tabular}

atients with lesions confined to the extradural compartment $(n=4)$ and mild head injuries $(n=7)$ were excluded from analysis. atients with mild head injury $(n=7)$ were excluded from analysis.

situated in sites purportedly relevant to dichotic listening as compared with the 37 patients in the low risk group. This impression was confirmed by both an analysis of variance of the ranks of the laterality coefficient, $F(1,60)=4.83, p<0.04$ and a significant relationship between extreme right ear advantage $(>64)$ and intrahemispheric localisation of lesion, Chi-square $(1, \mathrm{df})=5.71, \mathrm{p}<0.02$. The groups at high versus low risk for extreme ear asymmetry did not differ with respect to age, $F(1,60)=0 \cdot 18, p<0.68$ or education, $F(1,60)=0.97, p<0.33$. A pattern of lower GCS scores in the patients at greater risk for hemispheric disconnection fell short of significance, $F(1,60)=2 \cdot 54, p<0 \cdot 12$. Similarly, duration of impaired consciousness (that is, until the patient consistently obeyed commands) also tended to be longer in patients with strategic localisation of lesion (table 1), but this difference was also nonsignificant, $F(1,60)=2.78, p<0.11$. In addition, the interval between injury and and the dichotic listening test was longer in the patients at risk for extremely asymmetric performance, a difference which approached signifi- cance, $F(1,60)=3 \cdot 49, p<0 \cdot 07$. An assessment of the effects of lateralisation of lesion on performance was not feasible because of insufficient numbers of patients with unilateral insults which could be matched for depth.

The MRI findings of the four severely injured patients who exhibited a left ear advantage included left pontine, left frontal white matter, and bilateral frontal cortical lesions in patient 1 ; bilateral frontal white matter lesions in patient 2; left frontal cortical contusion in patient 3; bifrontal contusions extending into the white matter on the left in patient 4 . Of the four patients with mild to moderate head injury who had a left ear advantage, the first patient had bifrontal lesions extending into the white matter and a right temporal cortical lesion. The second patient had a left parietotemporal white matter lesion and right periventricular white matter lesion; the third patient had a left frontal cortical lesion, whereas the fourth patient had a right frontotemporal cortical lesion. We concluded that MRI revealed no distinctive localisation of brain lesion in patients with left ear advantage.

Table 2 Relationship between dichotic listening performance and other measures of hemispheric integration

\begin{tabular}{|c|c|c|c|c|}
\hline & \multirow[b]{2}{*}{ Writing to dictation } & \multirow[b]{2}{*}{ Tactile naming } & \multicolumn{2}{|c|}{ Gesture matching } \\
\hline & & & Ipsilateral & Contralateral \\
\hline $\begin{array}{l}\text { Patients with exaggerated asymmetry on } \\
\text { dichotic listening* } \\
\text { Right ear advantage }(n=15)\end{array}$ & $(n=6)$ & $(n=11)$ & $(n=14)$ & $(n=14)$ \\
\hline $\begin{array}{l}\text { Errors present } \\
\text { No errors } \\
\text { Left ear advantage }(n=7) \\
\text { Errors present } \\
\text { No errors }\end{array}$ & $\frac{\begin{array}{l}4 \\
2 \\
(n=3)\end{array}}{1}$ & $\frac{\begin{array}{l}6 \\
5 \\
(n=4) \\
2\end{array}}{2}$ & $\begin{array}{l}2 \\
12 \\
(n=4) \\
\frac{1}{3}\end{array}$ & $\frac{\begin{array}{l}3 \\
11 \\
(n=4)\end{array}}{1}$ \\
\hline $\begin{array}{l}\text { Patients without exaggerated asymmetry }(n=47) \\
\text { Errors present } \\
\text { No errors }\end{array}$ & $\begin{array}{l}\frac{(\mathrm{n}=32)}{15} \\
17\end{array}$ & $\frac{(\mathrm{n}=30)}{17}$ & $\frac{(n=30)}{6}$ & $\frac{(n=29)}{5}$ \\
\hline
\end{tabular}

*Exaggerated asymmetry was defined as a laterality index outside the range of the control group (that is, $>64)$. 

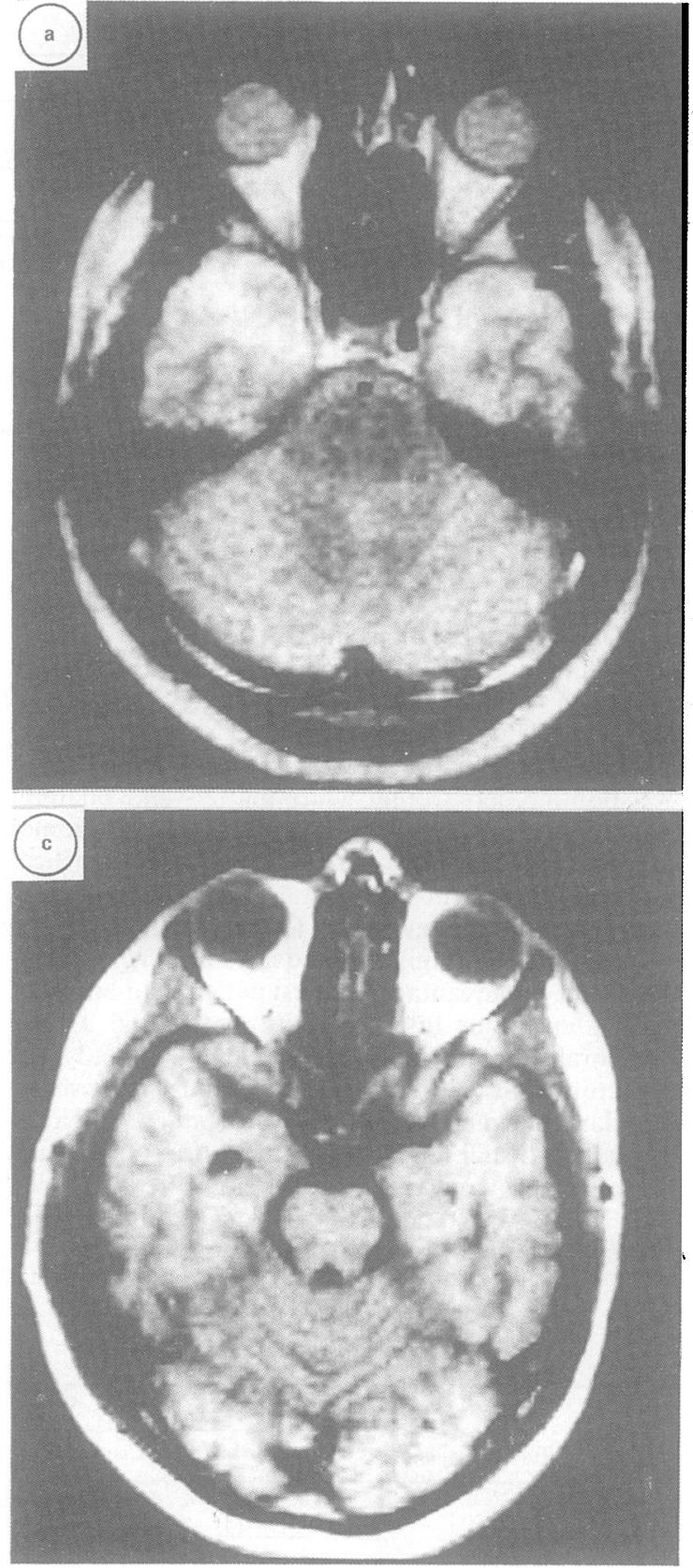

Writing, matching hand postures, tactile naming Writing to dictation, matching hand postures and tactile naming were analysed according to the presence of any errors. Table 2 summarises the pattern of errors by CHI patients on these tests, whereas the data of control subjects are not shown because their perfor-

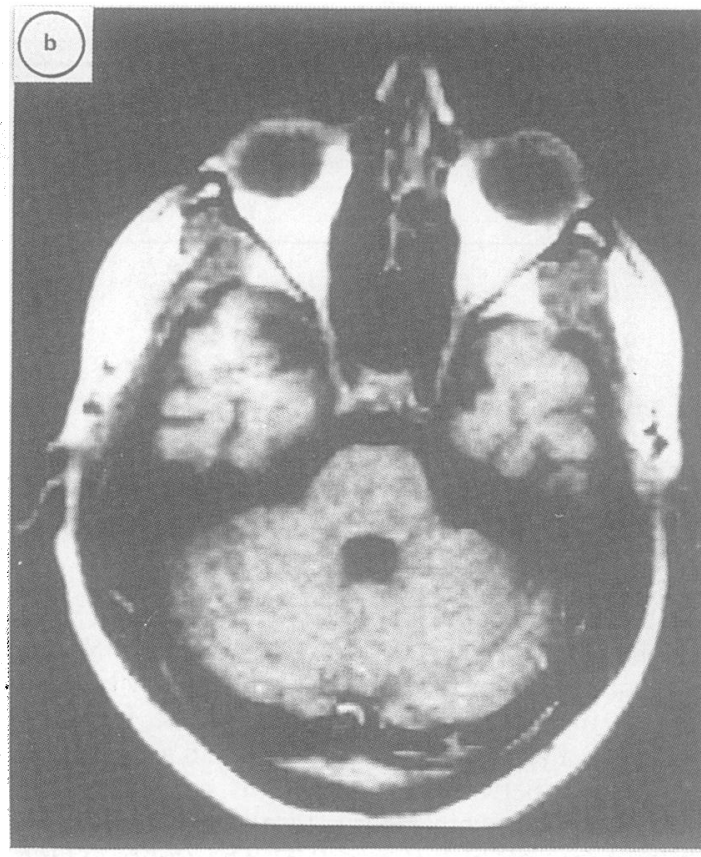

Fig $2 T_{2}$-weighted $M R$ image $(T R=2 \cdot 0, T E=56)$ obtained three months after this 21 year old right handed man (PS) sustained a moderate (GCS score $=10$ ) closed head injury in a motor car accident. Increased intensity in the anterior inferior portion of the right temporal lobe is present (A). Focal atrophy in the right temporal region including enlargement of right temporal horn, is seen on the $T_{\text {,-weighted }}(T R=0.5, T E=28)$ images $(B, C)$. This patient exhibited total left ear suppression on dichotic listening despite bilaterally preserved tactile naming, transfer of hand postures and writing.

mance was essentially flawless. It is seen that errors in writing to dictation and naming objects palpated in the absence of visual cues were relatively common as compared with the infrequent errors in duplicating gestures using either the ipsilateral or contralateral of hand. The moderate to severely injured patients were $N$ 


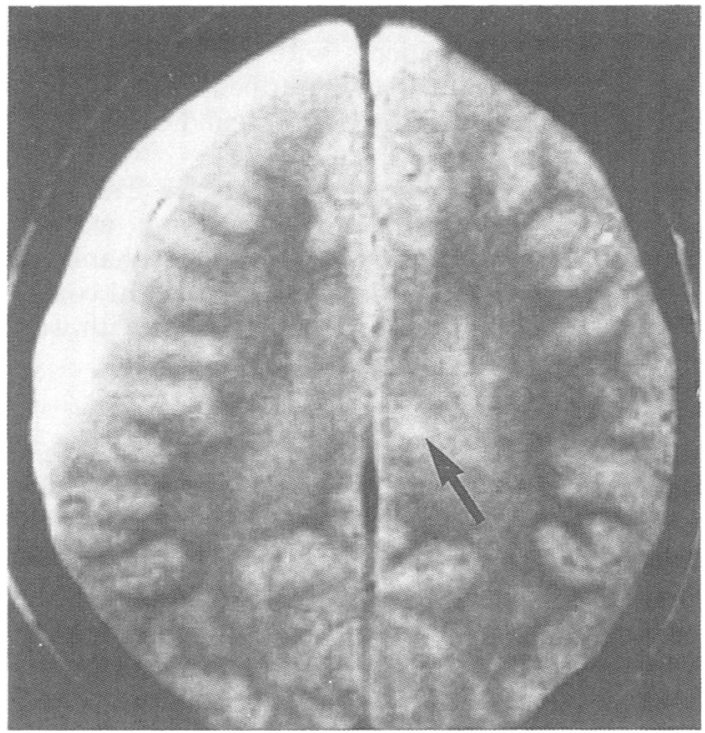

Fig $3 T_{2}$-weighted $M R$ image $(T R=2 \cdot 0, T E=30)$ obtained 12 months after this 17 year old right handed woman $(M H)$ sustained a severe head injury (GCS score $=6$, duration of impaired consciousness $=25$ days) shows a focal area of increased intensity in the left body of the corpus callosum anterior to the splenium. CT findings were limited to a right frontoparietal subdural fluid collection (also present on MRI). In contrast to patient PS, this young woman exhibited hemispheric disconnection limited to impaired left tactile naming and contralateral transfer of postures despite a normal right ear advantage on dichotic listening.

more likely to commit errors on each test than the controls (Fisher's Exact method, $p<0.01$ ). In contrast, the probability of patients with mild injuries committing errors on these tests was similar to controls $(p>0.05)$. There was also no indication that MRI evidence of lesions involving the white matter was related to a greater likelihood of errors on these tests than other patients who sustained injuries producing similar impairment of consciousness ( $p>$ 0.05 ).

\section{Dissociation between dichotic listening and other tests} of hemispheric disconnection

Table 2 shows that a marked ear advantage on dichotic listening was not invariably associated with difficulties in tactile naming, writing to dictation, or reproducing postures either ipsilaterally or contralaterally. This dissociation is illustrated in fig 2 which depicts the MRI scan of a 21 year old man (PS) who exhibited complete left ear suppression in dichotic listening despite bilaterally normal performance on tactile naming, matching postures and writing. This patient was studied for three months after sustaining a moderate CHI (GCS score $=10)$.

In contrast, fig 3 shows the MRI scan of a young, right handed woman (MH) who had difficulty in both tactile naming and matching postures using her left hand despite bilaterally preserved writing and a normal right ear advantage on dichotic listening (laterality index $=20$ ). As shown in fig 3, MRI visualised a lesion in the body of the corpus callosum anterior to both the splenium and the presumed location of the auditory callosal pathways. ${ }^{112}$ This patient demonstrated a striking tactile-verbal disconnection which was confined to processing material presented to her left hand in the absence of visual cues. She accurately identified 15 out of 16 common objects palpated with her right hand, and in contrast could name only two (13\% correct) using her left hand (for example, a watch was described as a "little chain thing"). Anomic errors for objects presented to the left hand reflected partially correct identification of their sensory qualities despite failure to associate the physical features with the appropriate name. This asymmetry in tactile naming could not be attributed to a generalised anomia as reflected by intact naming of objects which were placed in her right hand or presented visually. Moreover, this tactile anomia could not be ascribed to a sensory deficit as the patient (MH) correctly selected objects from a visual array which she had palpated with her left hand. When asked to feel for objects which were named by the examiner, her mean search time using her left hand was $15.0 \mathrm{~s}$ as compared with $10.0 \mathrm{~s}$ using her right hand. Although the patient had no errors in ipsilateral matching of hand postures using her right hand, she had one error on the left side and three errors in matching postures using the contralateral hand.

\section{Discussion}

Consistent with the MRI evidence for multifocal lesions which frequently involved the cerebral white matter, exaggerated asymmetry was predicted on the dichotic listening test and on other measures of hemispheric integration. The longer anatomic pathway involved in processing left ear verbal input (or using the left hand to palpate objects to be named or to write) includes interhemispheric fibres connecting right auditory cortex to Wernicke's area and intrahemispheric connections (for example, from left somatosensory cortex to left perisylvian speech areas to name objects palpated by right hand). In view of evidence that even partial section of the corpus callosum may be sufficient to produce left ear suppression, ${ }^{25}$ it is plausible that injury to callosal fibres 
contributed to the left ear suppression exhibited by a subgroup of our patients. Similar to our finding of a relationship between exaggerated ear asymmetry and traumatic cerebral white matter lesions documented by MRI, dichotic listening studies have shown left ear suppression in patients with multiple sclerosis. ${ }^{2627}$ However, a rival explanation of the exaggerated right ear advantage in our patients would invoke attentional deficit. ${ }^{28}$ The results provide no compelling reason to reject an attentional deficit interpretation.

Our findings have implications for the clinical evaluation of postacute patients sustaining severe $\mathrm{CHI}$. The asymmetry in dichotic listening performance exhibited by a subgroup of the moderate to severely injured patients is not readily explained by a global cognitive impairment which would presumably impair processing of material presented to either ear. Similarly, it is unlikely that difficulty in copying simple hand postures, naming common objects presented to either hand, or unilateral dysgraphia can be attributed to intellectual deficit. Contrary to an interpretation based on global cognitive deficit, marked asymmetries in dichotic listening performance were frequently dissociated from defects on the manual and tactile tests (table 2). Patients who sustained a mild head injury had a moderate right ear advantage in dichotic listening performance similar to uninjured right handed control subjects. Moreover, mild CHI patients had no difficulty in performing hand postures (both ipsilateral and contralateral matching), naming palpated objects or writing with either hand. Consequently, we suggest that left ear suppression under dichotic listening and defects in intermanual transfer of information are among the constellation of neurobehavioural sequelae of severe $\mathrm{CHI}$.

The presence of errors on the manual and somatosensory tests of interhemispheric integration was related to severity of injury, but not to the presence of exaggerated right ear advantage. As reported in studies of postcommissurotomy patients ${ }^{1920}$ and experimental investigations of fibre degeneration after callosal lesions, ${ }^{24}$ portions of the corpus callosum body which subserve somatosensory information are anterior to the callosal auditory pathways. Moreover, disruption of intrahemispheric connections could selectively disturb performance on somatosensory or auditory tasks.

Our findings corroborate and extend previous studies of behavioural disconnection after $\mathrm{CHI}^{8-11}$ and indicate that both the clinical features and their neuroanatomic substrate are heterogeneous. This variability in disconnection symptoms and localisation of brain lesion is compatible with observations by Strich $^{12}$ that nerve fibres in a specific plane were often totally disrupted despite preservation of adjacent fibres running in a different direction. Finally, our finding that cortical lesions were also present in the preponderance of patients with deep parenchymal lesions is consistent with the centripetal model of head injury effects proposed by Ommaya and Gennarelli. ${ }^{15}$

This study was supported by grants NS 21889 , the Javits Neuroscience Investigator Award, and the Moody Foundation Grant 84-152A. We thank S F $\stackrel{?}{\mathrm{O}}$ Handel and A M Goldman for radiological consultations and Liz Zindler for her assistance with word processing.

\section{References}

1 Strich SJ. Diffuse degeneration of the cerebral white matter in severe dementia following head injury. $J$ Neurol Neurosurg Psychiatry 1956;19:163-85.

2 Strich SJ. Lesions in the cerebral hemispheres after blunt head injury. In: Sevitt S, Stoner HB, eds. The Pathology of Trauma. London: BMA, 1970:166-71.

3 Adams JH, Graham DI, Murray LS, Scott G. Diffuse axonal injury due to nonmissile head injury in humans: an analysis of 45 cases. Ann Neurol 1982;12:557-63.

4 Lindenberg R, Fisher RS, Durlacher SH, Lovitt WV Jr, Freytag E. iv Lesions of the corpus callosum following blunt mechanical trauma to the head. Am J Pathol 1955;31:297-317.

5 Adams JH, Graham D, Scott G, Parker LS, Doyle D. Bra每 damage in fatal non-missile head injury. J Clin Pathol 1980 33:1132-45.

6 Levin HS, Meyers CA, Grossman RG, Sarwar M. Ventricul\& enlargement after closed head injury. Arch Neurol 1981;3 623-9.

7 Chester CS, Reznick BR. Ataxia after severe head injury: the pathological substrate. Ann Neurol 1987;22:77-9.

8 Lhermitte J, Massary J de, Huguenin R. Syndrome occipital ave alexie pure d'origine traumatique, par. Rev Neurol (Paris) $19 x \overline{2}$ 2:703-7.

9 Rubens AB, Geschwind N, Mahowald MW, Mastri A. Posttraumatic cerebral hemispheric disconnection syndrome. Arch Neurol 1977;34:750-5.

10 Levin HS, Grossman RG, Sarwar M, Meyers CA. Linguistic recovery after closed head injury. Brain Lang 1981;12:360-74.

11 Alexander MP, Warren RL. Localization of callosal auditory pathways: A CT case study. Neurology 1988;38:802-4.

12 Oppenheimer DR. Microscopic lesions in the brain following head injury. J Neurol Neurosurg Psychiatry 1968;31:299-306.

13 Levin HS, Williams D, Crofford MJ, et al. Relationship of depth of brain lesions to consciousness and outcome after closed head injury. $J$ Neurosurg 1988;69:861-6.

14 Wilson JTL, Wiedmann KD, Hadley DM, Concon B, Teasdale G, Brooks DN. Early and late magnetic resonance imaging and neuropsychological outcome after head injury. $J$ Neurol Neurosurg Psychiatry 1988;51:391-6.

15 Ommaya AK, Gennarelli TA. Cerebral concussion and traumatic unconsciousness: correlation of experimental and clinical observations on blunt head injuries. Brain 1974;97:633-54.

16 Bentin S, Sahar A, Moscovitch M. Intermanual information transfer in patients with lesions in the trunk of the corpus callosum. Neuropsychologia 1984;22:601-11.

17 Dimond SJ, Scammell RE, Brouwers EYM, Weeks R. Functions of the centre section (trunk) of the corpus callosum in man. Brain 1977;100:543-62.

18 Damasio H, Damasio A. "Paradoxic" ear extinction in dichotic listening: possible anatomic significance. Neurology 1979;29: 644-53. 
19 Sparks R, Geschwind H. Dichotic listening in man after section of neocortical commissures. Cortex 1968;4:3-16.

20 Springer SP, Gazzaniga MS. Dichotic testing of partial and complete split brain subjects. Neuropsychologia 1975;13:341-6.

21 Levin HS, Mattis S, Ruff RM, et al. Neurobehavioral outcome following minor head injury: a three-center study. $J$ Neurosurg 1987;66:234-43.

22 Teasdale G, Jennett B. Assessment of coma and impaired consciousness: a practical scale. Lancet 1974;ii:81-4.

23 Spreen O, Benton AL. Neurosensory Center Comprehensive Examination for Aphasia: manual of Directions. Victoria, BC: Neuropsychology Laboratory, University of Victoria, 1969.

24 Pandya DN, Karol EA, Heilbronn D. The topographical distribu- tion of interhemispheric projections in the corpus callosum of the rhesus monkey. Brain Res 1971;32:31-43.

25 Wale J, Geffen G. Hemispheric specialization and attention: effects of complete and partial callosal section and hemispherectomy on dichotic monitoring. Neuropsychologia 1986;24: 483-96.

26 Rubens AB, Froehling B, Slater G, Anderson D. Left ear suppression on verbal dichotic tests in patients with multiple sclerosis. Ann Neurol 1985;18:459-63.

27 Jacobson JT, Deppe U, Murray TJ. Dichotic paradigms in multiple sclerosis. Ear Hear 1983;4:311-7.

28 Geffen G, Quinn K. Hemispheric specialization and ear advantages in processing speech. Psychol Bull 1984;96:273-91. 